\title{
Correction to: Global Value Chains and Local Business Environments: Which Factors Really Matter in Developing Countries?
}

\author{
Marion Dovis ${ }^{1} \cdot$ Chahir Zaki $^{2}$
}

Published online: 25 July 2020

(c) Springer Science+Business Media, LLC, part of Springer Nature 2020

\section{Correction to: Review of Industrial Organization https://doi.org/10.1007/s11151-020-09768-w}

In the original publication of the article, the research grant information was inadvertently missed in the acknowledgement section. The correct acknowledgment section should read as given below:

This work was supported by French National Research Agency Grants ANR17-EURE-0020 and a research Grant financed by the Economic Research Forum (Cairo, Egypt). We are grateful to Bernard Hoekman (European University Institute) and David C. Francis (World Bank) for their constructive comments.

Also, the affiliation of the first author was published with an error. The correct affiliation should read as given below:

Aix-Marseille Univ., CNRS, EHESS, Centrale Marseille, IRD, AMSE, Marseille, France.

Publisher's Note Springer Nature remains neutral with regard to jurisdictional claims in published maps and institutional affiliations.

The original article can be found online at https://doi.org/10.1007/s11151-020-09768-w.

Chahir Zaki

chahir.zaki@feps.edu.eg

Marion Dovis

marion.dovis@univ-amu.fr

1 Aix-Marseille Univ., CNRS, EHESS, Centrale Marseille, IRD, AMSE, Marseille, France

2 Faculty of Economics and Political Science, Cairo University and ERF, Giza, Egypt 